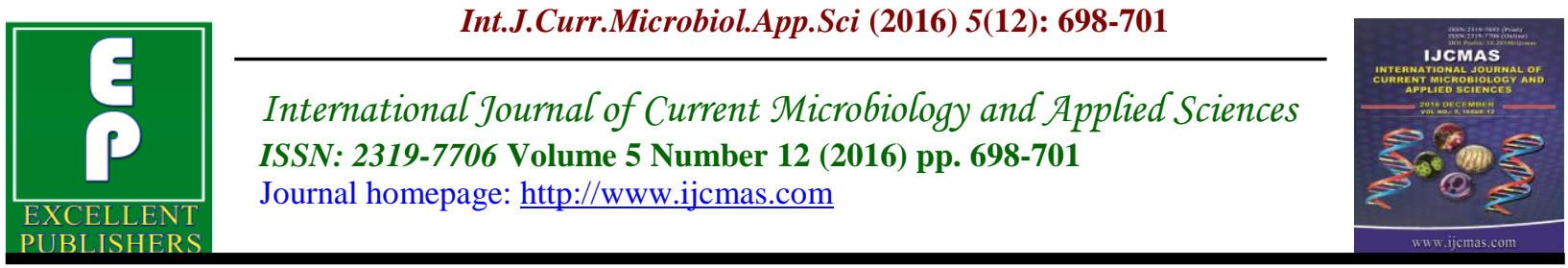

Original Research Article

http://dx.doi.org/10.20546/ijcmas.2016.512.079

\title{
Study of Epidemiological Profile and Analysis of Platelet Count of Dengue Cases
}

\author{
Roshni Pranav Patel and Minalben Bharat Kumar Trivedi*
}

Department of Microbiology, GMERS Medical College, Himmatnagar, India

*Corresponding author

\begin{tabular}{|c|c|}
\hline & A B S T R A C T \\
\hline $\mathrm{rds}$ & $\begin{array}{l}\text { Dengue fever is a major cause of illness and death worldwide. There are currently } \\
\text { no licensed vaccines or specific therapeutics, and substantial vector control efforts }\end{array}$ \\
\hline $\begin{array}{l}\text { Dengue, } \\
\text { epidemiology, } \\
\text { platelet count. } \\
\text { Aedes aegypti } \\
\text { and Aedes } \\
\text { albopictus }\end{array}$ & $\begin{array}{l}\text { have not stopped its rapid emergence and global spread. The study aims to } \\
\text { bringing to light the changing epidemiological pattern of dengue and analyze } \\
\text { platelet count. The retrospective analysis of the data of laboratory confirmed } \\
\text { dengue cases from Jan } 2015 \text { to Jun } 2016 \text { was done to study epidemiological pattern } \\
\text { and analysis platelet count. Total } 51 \text { cases were studied. Male to female ratio was }\end{array}$ \\
\hline Article Info & hospital within 3 days of onset of illness for seeking treatment \& $70 \%$ cases had \\
\hline $\begin{array}{l}\text { Accepted: } \\
\text { 26 November } 2016 \\
\text { Available Online: } \\
10 \text { December } 2016\end{array}$ & $\begin{array}{l}\text { platelet count less than } 1,00,000 / \text { cumm. Dengue affects male younger population } \\
\text { predominantly. Symptoms are so alarming that majority of dengue cases seek } \\
\text { treatment early in the course of disease within } 3-5 \text { days and majority reveals } \\
\text { platelet count less than } 1,00,000 / \text { cumm }\end{array}$ \\
\hline
\end{tabular}

\section{Introduction}

The disease is caused by dengue virus which gets transmitted to humans by the bites of infected mosquitoes, Aedes aegypti and Aedes albopictus (Tang et al., 2012). The incidence of dengue has grown dramatically around the world in recent decades (http://www.who.int/mediacentre/fact sheets /fs117/en/).One recent estimate indicates 390 million dengue infections per year, of which 96 million manifest clinically (with any severity of disease) (Bhatt et al., 2013).

The year 2015 was characterized by large dengue outbreaks worldwide. An estimated
$5,00,000$ people with severe dengue require hospitalization each year, a large proportion of whom are children. About $2.5 \%$ of those affected die (http://www.who.int/ media centre/ factsheets/fs117/en/).There are currently no licensed vaccines or specific therapeutics, and substantial vector control efforts have not stopped its rapid emergence and global spread (Tatem et al., 2006).

This article aims to analysis \& bringing light the current epidemiological and clinical status of the dengue fever. 


\section{Materials and Methods}

The study was done by retrospective analysis of the data of laboratory confirmed dengue cases from January 2015 to jun 2016.We performed ELISA for dengue NS1 antigen or dengue $\operatorname{IgM}$ on serum samples depending upon the duration of illness, after receiving test request for dengue suspected cases from the hospital. The dengue suspected case with positive dengue ELISA test was considered as confirmed dengue case. The laboratory confirmed dengue cases data were studied to analyze the epidemiological pattern and platelet count.

\section{Results and Discussion}

Out of total 51 dengue cases studied, 32 cases were male and 19 were female. The male to female ratio was 1.7:1.

Dengue fever represents a real economic burden especially in affected countries. Extensive efforts are needed to tackle disease spread and reduce the mortality rates and the associated healthcare cost (Taoufik
Nedjadi et al., 2015). It has been estimated that the number of misdiagnosed dengue cases could reach a record ratio of $50 \%$ of all cases, mainly due to a large disparity of dengue signs and symptoms which overlap with the symptoms of other viral infections, especially for persons living in or traveling to endemic areas of tropical infectious diseases (Malavige et al., 2004).

In our study majority of dengue cases were falling in younger age group up to 20 years (74\%) while adult population were less affected. Only $8 \%$ cases were reported in more than 30 years age group. Most of the dengue studies done in India shows younger population predominantly involved(PM Ukey et al., 2010; Jayashree et al., 2011; Ashwini Kumar et al., 2010; Pruthvi et al., 2012). While dengue study done by Anker $e t$ al., in six asian countries reveal higher age shift to involve more adult cases. It may be due to lowered herd immunity .Our study shows predominantly male affected, which correlates with majority of studies (Ukey et al., 2010; Jayashree et al., 2011).

Table.1 Age profile of dengue cases

\begin{tabular}{|c|c|c|}
\hline Age(years) & No. of dengue cases & \% of dengue cases \\
\hline $0-10$ & 19 & $37 \%$ \\
\hline $11-20$ & 19 & $37 \%$ \\
\hline $21-30$ & 9 & $18 \%$ \\
\hline $31-40$ & 2 & $4 \%$ \\
\hline$>40$ & 2 & $4 \%$ \\
\hline
\end{tabular}

Table.2 The duration from the onset of illness to blood collection on suspicion of dengue

\begin{tabular}{|c|c|c|}
\hline $\begin{array}{l}\text { No. of days from the onset of } \\
\text { illness to blood collection on } \\
\text { suspicion of dengue }\end{array}$ & $\begin{array}{c}\text { Total cases } \\
\text { (no.) }\end{array}$ & $\begin{array}{c}\text { Total cases } \\
\text { (percentage) }\end{array}$ \\
\hline $1-3$ & 22 & $43 \%$ \\
\hline $4-6$ & 21 & $41 \%$ \\
\hline $7-9$ & 5 & $10 \%$ \\
\hline$>9$ & 3 & $6 \%$ \\
\hline
\end{tabular}


Table.3 Profile of platelet count

\begin{tabular}{|l|c|c|}
\hline Platelet count $(/$ cumm) & No. of cases & \% of cases \\
\hline$<50,000$ & 16 & $31.4 \%$ \\
\hline $50,000-1,00,000$ & 20 & $39.2 \%$ \\
\hline $1,00,000-1,50,000$ & 8 & $15.7 \%$ \\
\hline$>1,50,000$ & 7 & $13.7 \%$ \\
\hline
\end{tabular}

Graph.1 Month wise distribution of dengue cases

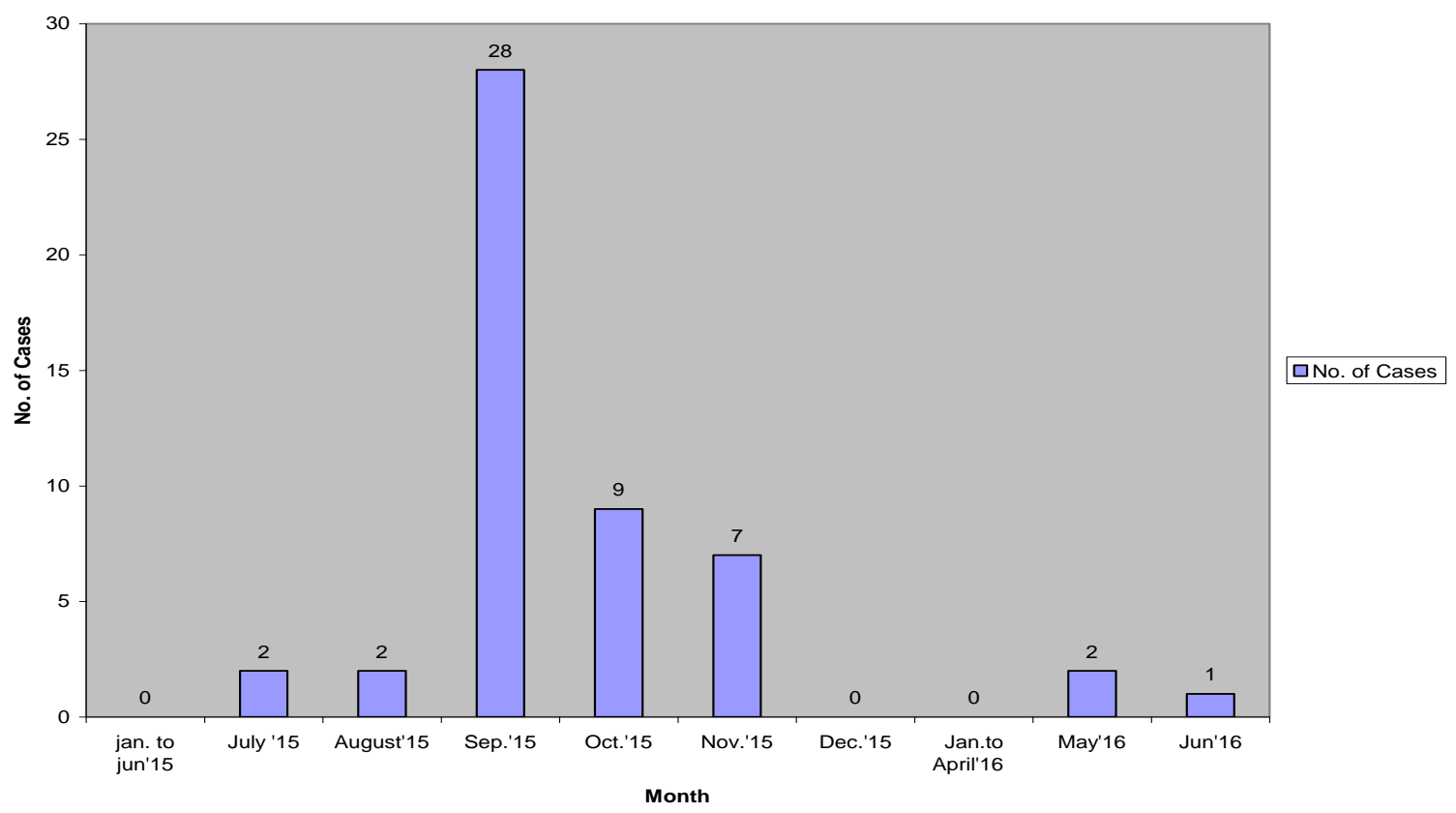

The majority of cases seek treatment early in course of illness within first week. In our study $43 \%$ cases was presented in hospital within 3 days and $84 \%$ within 6 days.

In our study, majority of cases (70\%) shows platelet count below 1,00,000/cumm, which correlates with studies done by Pruthvi et al., Jayashree et al.. However, study done by Pruthvi et al. shows only $9 \%$ cases having platelet count more than $1,00,000 /$ cumm.

In 2015, No case was appeared from January to jun. Cases starts to appear from July (monsoon period) but peak occurred from September and last up to November (post monsoon period), which correlates with usual seasonal epidemiological pattern of dengue (Gupta et al., 2005; Kaur et al.,1997; Ukey et al., 2010). It may be due to very favorable condition for high breeding of the vector mosquito, i.e., Aedes aegypti in this period. This seasonal outbreak of disease transmission is very important at local level for effective control measures (Ukey et al., 2010).

In conclusion, male younger population are predominantly affected in dengue. Majority of dengue cases seek treatment early in course of disease within 3-5 days due to alarming symptoms and reveals platelet count less than 1,00,000/cu mm. Majority of dengue outbreak occurs in post monsoon period, so effective preventive strategies should be planned accordingly.

\section{References}

Anker, M. and Arima, Y. 2011. Male-female 
differences in the number of reported incident dengue fever cases in six Asian countries. Western Pacific Surveillance and Response J., 2(2): 17-23.

Ashwini Kumar, Chythra, R., Rao, Vinay Pandit, Seema Shetty, Chanaveerappa Bammigatti and Charmaine Minoli Samarasinghe. et al. 2010. Clinical Manifestations and Trend of Dengue Cases Admitted in a Tertiary Care Hospital, Udupi District, Karnataka. Indian J. Community Med., 35(3).

Bhatt, S., Gething, P.W., Brady, O.J., Messina, J.P., Farlow, A.W., Moyes, C.L. et al. 2013. The global distribution and burden of dengue. Nature, 496: 504-507.

Gupta, E., Dar, L., Narang, P., Srivastava, V.K., Broor, S. 2005. Serodiagnosis of dengue during an outbreak at a tertiary care hospital in Delhi. Indian J. Med. Res., 121: 36-8.

Kaur, H., Prabhakar, H., Mathew, P., Marshalla, R., Arya, M. 1997. Dengue haemorrhagic fever outbreak in October-November 1996 in Ludhiana, Panjab, India. Indian J. Med. Res., 106: 1-3.

Jayashree, K., G.C. Manasa, P. Pallavi, and G.V. Manjunath. 2011. Evaluation of Platelets as Predictive Parameters in Dengue Fever. Indian J. Hematol. Blood Transfus., 27(3): 127-130.

Malavige, G.N., Fernando, S., Fernando, D.J., Seneviratne, S.L. 2004. Dengue viral infections. Postgrad. Med. J., 80: 588-601.

Ukey, P.M., $\quad$ S.A. $\quad$ Bondade, P.V. Paunipagar, R.M. $\quad$ Powar and S.L. Akulwar. 2010. Study of Seroprevalence of Dengue Fever in Central India. Indian J Community Med., 35(4): 517-519.

Pruthvi, D., Shashikala, P., Shenoy, V. 2012. Evaluation of Platelet Count in Dengue Fever Along with Seasonal Variation of Dengue Infection. $J$. Blood Disord. Transfus., 3: 128.

Tang, K.F., Ooi, E.E. 2012. Diagnosis of dengue: An update. Expert Rev. Anti Infect. Ther., 10(8): 895-907.

Taoufik Nedjadi, Sherif El-Kafrawy, Sayed S. Sohrab, Philippe Despres, Ghazi Damanhouri, Esam Azhar. et al. 2015. Trackling dengue fever: Current status and challenges. Virol. J., 12: 212.

Tatem, A.J., Hay, S.I. \& Rogers, D.J. 2006. Global traffic and disease vector dispersal. Proc. Natl Acad. Sci. USA, 103: 6242-6247.

\section{How to cite this article:}

Roshni Pranav Patel and Minalben Bharat Kumar Trivedi. 2016. Study of Epidemiological Profile and Analysis of Platelet Count of Dengue Cases. Int.J.Curr.Microbiol.App.Sci. 5(12): 698-701. doi: http://dx.doi.org/10.20546/ijcmas.2016.512.079 